\title{
Osmotically Controlled Drug Delivery System with Associated Drugs
}

\author{
Brahma P Gupta*, Navneet Thakur, Nishi P Jain, Jitendra Banweer, Surendra Jain
}

Sagar Institute of Research \& Technology-Pharmacy, SIRT- Campus, Ayodhya by-pass road, Bhopal, Madhya Pradesh, India.

Received, May 18, 2010; Revised, September 10, 2010; Accepted, October 28, 2010; November 20, 2010.

\begin{abstract}
Conventional drug delivery systems have slight control over their drug release and almost no control over the effective concentration at the target site. This kind of dosing pattern may result in constantly changing, unpredictable plasma concentrations. Drugs can be delivered in a controlled pattern over a long period of time by the controlled or modified release drug delivery systems. They include dosage forms for oral and transdermal administration as well as injectable and implantable systems. For most of drugs, oral route remains as the most acceptable route of administration. Certain molecules may have low oral bioavailability because of solubility or permeability limitations. Development of an extended release dosage form also requires reasonable absorption throughout the gastro-intestinal tract (GIT). Among the available techniques to improve the bioavailability of these drugs fabrication of osmotic drug delivery system is the most appropriate one. Osmotic drug delivery systems release the drug with the zero order kinetics which does not depend on the initial concentration and the physiological factors of GIT. This review brings out new technologies, fabrication and recent clinical research in osmotic drug delivery.
\end{abstract}

\section{INTRODUCTION}

Many conventional drug delivery systems have been designed by various researchers to modulate the release a drug over an extended period of time and release (1). The rate and extent of drug absorption from conventional formulations may vary greatly depending on the factors such as physico-chemical properties of the drug, presence of excipients, physiological factors such as presence or absence of food, $\mathrm{pH}$ of the gastro-intestinal tract (GI) and so on (2). However, drug release from oral controlled release dosage forms may be affected by $\mathrm{pH}$, GI motility and presence of food in the GI tract (3). Drugs can be delivered in a controlled pattern over a long period of time by the process of osmosis. Drug delivery from this system is not influenced by the different physiological factors within the gut lumen and the release characteristics can be pre-dicted easily from the known properties of the drug and the dosage form (4).

Osmotically controlled drug delivery system, deliver the drug in a large extent and the delivery nature is independent of the physiological factors of the gastrointestinal tract and these systems can be utilized for systemic as well as targeted delivery of drugs. Osmotically controlled oral drug delivery systems utilize osmotic pressure for controlled delivery of active agents (5).

Among the controlled release devices, osmotically controlled hold a stable place because of its reliability to deliver the API at predetermined zero order rate for prolonged period of time so these are used as the standard dosage forms for the constant delivery of contents.

Osmotic Pump Controlled Release Preparation is a novel drug delivery system with eternally drug delivery rate as characteristic and controlled with the osmotic pressure difference between inside and outside of the semipermeable membrane as drug delivery power (6).

Recently, osmotic tablets have been developed in which the delivery orifice is formed by the incorporation of a leachable component in the coating. Once the tablet comes in contact with the aqueous environment, the water-soluble component dissolves, and an osmotic pumping system results. Subsequently, water diffuses into the core through the microporous membrane, setting up an osmotic

Corresponding Author: Brahma Prakash Gupta; Sagar Institute of research \& technology-Pharmacy, Bhopal India; Email: guptabrahma@gmail.com 
gradient and thereby controlling the release of drug (7).Osmosis can be defined as the spontaneous movement of a solvent from a solution of lower solute concentration to a solution of higher solute concentration through an ideal semipermeable membrane, which is permeable only to the solvent but impermeable to the solute. The pressure applied to the higher-concentration side to inhibit solvent flow is called the osmotic pressure.

The first osmotic effect was reported by Abbe Nollet in 1748. Later in 1877, Pfeffer performed an experiment using semi-permeable membrane to separate sugar solution from pure water. He showed that the osmotic pressure of the sugar solution is directly proportional to the solution concentration and the absolute temperature. In 1886, Vant Hoff identified an underlying proportionality between osmotic pressure, concentration and temperature. He revealed that osmotic pressure is proportional to concentration and temperature and the relationship can be described by following equation.

$\pi=\mathrm{n}_{2} \mathrm{RT}$

Where, $\pi=$ osmotic coefficient

$\mathrm{n}_{2}=$ molar concentration of solute in the solution

$\mathrm{R}=$ gas constant

$\mathrm{T}=$ Absolute temperature

Osmotic pressure is a colligative property, which depends on concentration of solute that contributes to osmotic pressure. Solutions of different concentrations having the same solute and solvent system exhibit an osmotic pressure proportional to their concentrations. Thus a constant osmotic pressure, and thereby a constant influx of water can be achieved by an osmotic delivery system that results in a constant zero order release rate of drug (8).

The rate of drug release from osmotic pump depends on the drug solubility and the osmotic pressure of the core; hence, these systems are suitable for delivery of drugs with moderate water solubility (9).

\section{HISTORICAL ASPECTS OF OSMOTIC PUMPS}

About 75 years after discovery of the osmosis principle, it was first used in the design of drug delivery systems(10). Rose and Nelson, the Australian scientists, were initiators of osmotic drug delivery. In 1955, they developed an implantable pump, which consisted of three chambers: a drug chamber, a salt chamber contains excess solid salt, and a water chamber. The drug and water chambers are separated by rigid semipermeable membrane. The difference in osmotic pressure across the membrane moves water from the water chamber into the salt chamber. The volume of the salt chamber increases because of this water flow, which distends the latex diaphragm separating the salt and drug chambers, thereby pumping drug out of the device. The design and mechanism of this pump is comparable to modern push-pull osmotic pump. The major disadvantage of this pump was the water chamber, which must be charged before use of the pump. The pumping rate of this push-pull pump is given by the equation.

$$
\mathrm{dM} / \mathrm{dt}=\mathrm{dV} / \mathrm{dt} \times \mathrm{c}
$$

In general, this equation, with or without some modifications, applies to all other type of osmotic systems.

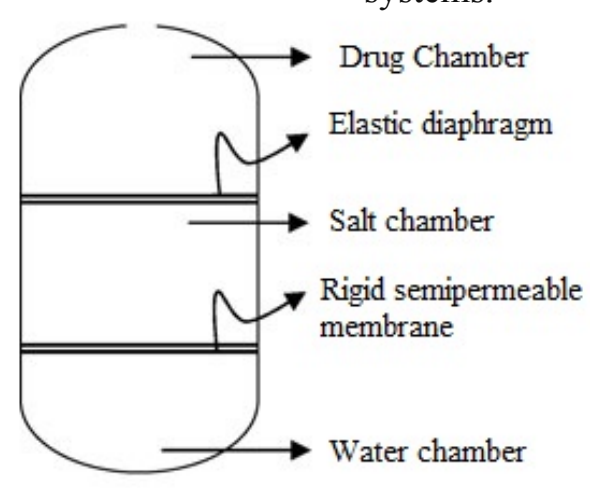

Figure 1. Rose-Nelson Pump 
Several simplifications in Rose-Nelson pump were made by Alza Corporation in early 1970s. The Higuchi-Leeper pump is modified version of RoseNelson pump. It has no water chamber and the device is activated by water imbibed from the surrounding environment. The pump is activated when it is swallowed or implanted in the body. This pump consists of a rigid housing, and the semipermeable membrane is supported on a perforated frame. It has a salt chamber containing a fluid solution with excess solid salt. Recent modification in Higuchi-Leeper pump accommodated pulsatile drug delivery. The pulsatile release was achieved by the production of a critical pressure at which the delivery orifice opens and releases the drug (11).

Further simplified variant of Rose-Nelson pump was developed by Higuchi and Theeuwes. This pump comprises a rigid, rate controlling outer semipermeable membrane surrounding a solid layer of salt coated on the inside by an elastic diaphragm and on the outside by the membrane. In use, water is osmotically drawn by the salt chamber, forcing drug from the drug chamber (12).

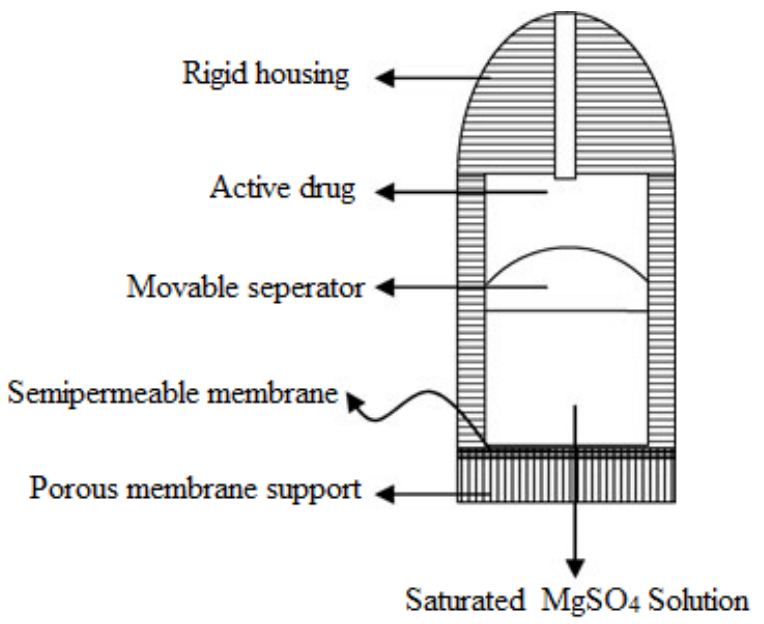

Figure 2. Higuchi-Leeper Pump

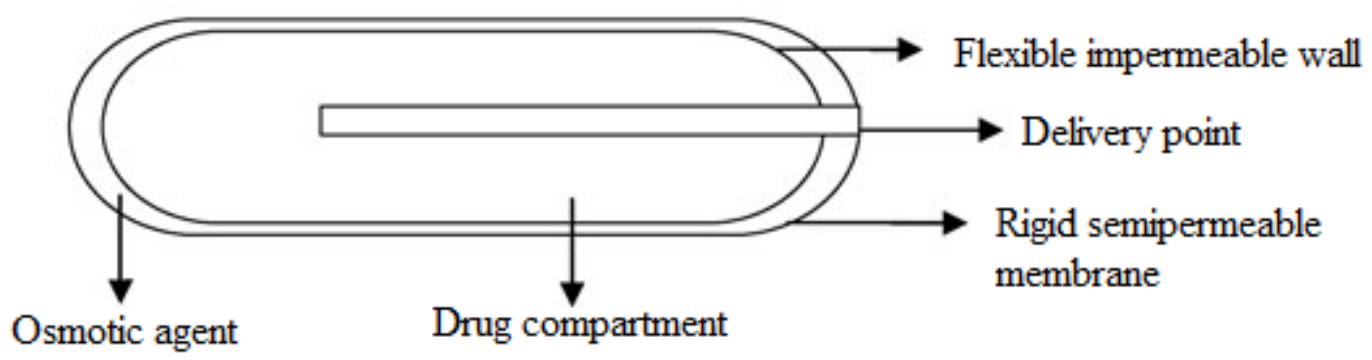

Figure 3. Theeuwes miniature osmotic pump 
In 1975, the major leap in osmotic delivery occurred as the elementary osmotic pump for oral delivery of drugs was introduced. The pump consists of an osmotic core containing the drug, surrounded by a semi permeable membrane with a delivery orifice. When this pump is exposed to water, the core imbibes water osmotically at a controlled rate, determined by the membrane permeability to water and by the osmotic pressure of the core formulation. As the membrane is nonexpandable, the increase in volume caused by the imbibitions of water leads to the development of hydrostatic pressure inside the tablet. This pressure is relieved by the flow of saturated solution out of the device through the delivery orifice. This process continues at a constant rate until the entire solid agent inside the tablet has been dissolved and only a solution filled coating membrane is left. This residual dissolved agent continues to be delivered at a declining rate until the osmotic pressure inside and outside the tablet is equal. Normally, the EOP delivers $60-80 \%$ of its contents at a constant rate, and there is a short lag time of $30-60 \mathrm{~min}$ as the system hydrates before zero order delivery from the EOP is obtained (13).

\section{ADVANTAGES OF OSMOTIC DRUG DELIVERY SYSTEMS}

Osmotic drug delivery systems for oral and parenterals use offer distinct and practical advantages over other means of delivery. The following advantages have contributed to the popularity of osmotic drug delivery systems $(14,15)$.

1. The delivery rate of zero-order is achievable with osmotic systems.

2. Delivery may be delayed or pulsed, if desired.

3. Higher release rates are possible with osmotic systems compared with conventional diffusion-controlled drug delivery systems.

4. The release rate of osmotic systems is highly predictable and can be programmed by modulating the release control parameters.

5. For oral osmotic systems, drug release is independent of gastric $\mathrm{pH}$ and hydrodynamic conditions.
6. The release from osmotic systems is minimally affected by the presence of food in gastrointestinal tract.

7. A high degree of in vivo- in vitro correlation (IVIVC) is obtained in osmotic systems.

\section{LIMITATIONS OF OSMOTIC DRUG DELIVERY SYSTEMS $(16,17)$}

1. Special equipment is required for making an orifice in the system.

2. Residence time of the system in the body varies with the gastric motility and food intake.

3. It may cause irritation or ulcer due to release of saturated solution of drug.

\section{KEY PARAMETERS THAT INFLUENCE THE DESIGN OF OSMOTIC CONTROLLED DRUG DELIVERY SYSTEMS}

\section{Orifice size}

To achieve an optimal zero-order delivery profile, the cross-sectional area of the orifice must be smaller than a maximum size to minimize drug delivery by diffusion through the orifice. Furthermore, the area must be sufficiently large, above a minimum size to minimize hydrostatic pressure buildup in the system. Otherwise, the hydrostatic pressure can deform the membrane and affect the zero-order delivery rate. Therefore, the cross-sectional area of the orifice should be maintained between the minimum and maximum values $(18,19)$.

Methods to create a delivery orifice in the osmotic tablet coating are:

- Mechanical drill

- Laser drill: This technology is well established for producing sub-millimeter size hole in tablets. Normally, CO2 laser beam (with output wavelength of $10.6 \mu$ ) is used for drilling purpose, which offers excellent reliability characteristics at low costs $(20,21)$.

- Indentation that is not covered during the coating process (22): Indentation is made in core tablets by using modified punches having needle on upper punch. This 
indentation is not covered during coating process which acts as a path for drug release in osmotic system.

- Use of leachable substances in the semipermeable coating : e.g. controlled porosity osmotic pump

\section{Solubility}

The release rate depends on the solubility of the solute inside the drug delivery system. Therefore, drugs should have sufficient solubility to be delivered by osmotic delivery. In the case of lowsolubility compounds, several alternate strategies may be employed. Broadly, the approaches can be divided into two categories. First, swellable polymers can be added that result in the delivery of poorly soluble drugs in the form of a suspension (23). Second, the drug solubility can be modified employing different methods such as co compression of the drug with other excipients, which improve the solubility (24). For example, cyclodextrin can be included in the formulation to enhance drug solubility (25). Additionally, alternative salt forms of the drug can be employed to modulate solubility to a reasonable level. In one case, the solubility of oxprenolol is decreased by preparing its succinate salt so that a reduced saturation concentration is maintained (26).

\section{Osmotic pressure}

The osmotic pressure $\pi$ directly affects the release rate. To achieve a zero-order release rate, it is essential to keep $\pi$ constant by maintaining a saturated solute solution. Many times, the osmotic pressure generated by the saturated drug solution may not be sufficient to achieve the required driving force. In this case, other osmotic agents are added that enhance osmotic pressure. For example, addition of bicarbonate salt not only provides the necessary osmotic gradient but also prevents clogging of the orifice by precipitated drug by producing an effervescent action in acidic media $(27,30)$.

\begin{tabular}{ll}
\hline Table 1. Osmotic pressures of saturated solution of commonly used osmogents \\
\hline Compounds of mixture & Osmotic pressure (atm) \\
\hline Lactose-Fructose & 500 \\
Dextrose-Fructose & 450 \\
Sucrose-Fructose & 430 \\
Mannitol-Fructose & 356 \\
Sodium chloride & 335 \\
Fructose & 250 \\
Lactose-Sucrose & 245 \\
Potassium chloride & 225 \\
Lactose-Dextrose & 225 \\
Mannitol-Dextrose & 190 \\
Dextrose-Sucrose & 170 \\
Mannitol-Sucrose & 150 \\
Sucrose & 130 \\
Mannitol-Lactose & 82 \\
Dextrose & 39 \\
Potassium sulphate & 38 \\
Mannitol & 36 \\
Sodium phosphate tribasic. 12H2O & 31 \\
Sodium phosphate dibasic. 7 H2O & 31 \\
Sodium phosphate dibasic. 12 H2O & 28 \\
Sodium phosphate monobasic. H2O & 21 \\
Sodium phosphate dibasic. Anhydrous & \\
\hline
\end{tabular}




\section{Semipermeable membrane}

Since the semipermeable membrane is permeable to water and not to ions, the release rate is essentially independent of the $\mathrm{pH}$ of the environment. Additionally, the drug dissolution process takes place inside the delivery system, completely separated from the environment (26).

\section{BASIC COMPONENTS OF OSMOTIC SYSTEMS \\ Drug}

Which have short biological half-life and which is used for prolonged treatment are ideal candidate for osmotic systems. Various drug candidates such as Diltiazem HCl, Carbamazepine, Metoprolol, Oxprenolol, Nifedipine, Glipizide etc are formulated as osmotic delivery.

\section{Semipermeable membrane}

An important part of the osmotic drug delivery system is the semipermeable membrane housing. Therefore, the polymeric membrane selection is key to the osmotic delivery formulation. The membrane should possess certain characteristics, such as impermeability to the passage of drug and other ingredients present in the compartments. The membrane should be inert and maintain its dimensional integrity to provide a constant osmotic driving force during drug delivery (28).

Any polymer that is permeable to water but impermeable to solute can be used as a coating material in osmotic devices. e.g. Cellulose esters like cellulose acetate, cellulose acetate butyrate, cellulose triacetate and ethyl cellulose and Eudragits (29).

\section{Osmotic agent}

Osmotic agents maintain a concentration gradient across the membrane. They also generate a driving force for the uptake of water and assist in maintaining drug uniformity in the hydrated formulation. Osmotic components usually are ionic compounds consisting of either inorganic salts or hydrophilic polymers. Osmotic agents can be any salt such as sodium chloride, potassium chloride, or sulfates of sodium or potassium and lithium. Additionally, sugars such as glucose, sorbitol, or sucrose or inorganic salts of carbohydrates can act as osmotic agents.
The polymers may be formulated along with poly(cellulose), osmotic solutes, or colorants such as ferric oxide. Swellable polymers such as poly(alkylene oxide), poly(ethylene oxide), and poly (alkalicarboxymethylcellulose) are also included in the push layer of certain osmotic systems. Further, hydrogels such as Carbopol (acidic carboxypolymer), Cyanamer (polyacrylamides), and Aqua-Keeps (acrylate polymer polysaccharides composed of condensed glucose units such as diester cross-linked polygluran) may be used.

\section{Flux regulators}

Delivery systems can be designed to regulate the permeability of the fluid by incorporating fluxregulating agents in the layer. Hydrophilic substances such as polyethethylene glycols (300 to $6000 \mathrm{Da})$, polyhydric alcohols, polyalkylene glycols, and the like improve the flux, whereas hydrophobic materials such as phthalates substituted with an alkyl or alkoxy (e.g., diethyl phthalate or dimethoxy ethylphthalate) tend to decrease the flux. Insoluble salts or insoluble oxides, which are substantially water-impermeable materials, also can be used for this purpose (8).

\section{Wicking agent}

A wicking agent is defined as a material with the ability to draw water into the porous network of a delivery device. A wicking agent is of either swellable or non-swellable nature. They are characterized by having the ability to undergo physisorption with water. Physisorption is a form of absorption in which the solvent molecules can loosely adhere to surfaces of the wicking agent via Vander Waals interactions between the surface of the wicking agent and the adsorbed molecule. The function of the wicking agent is to carry water to surfaces inside the core of the tablet, thereby creating channels or a network of increased surface area. Materials, which suitably for act as wicking agents include colloidal silicon dioxide, kaolin, titanium dioxide, alumina, niacinamide, sodium lauryl sulphate (SLS), low molecular weight poly vinyl pyrrolidone (PVP), m-pyrol, bentonite, magnesium aluminium silicate, polyester and polyethylene. 


\section{Pore forming agent}

These agents are particularly used in the pumps developed for poorly water soluble drug and in the development of controlled porosity or multiparticulate osmotic pumps. These poreforming agents cause the formation of microporous membrane. The microporous wall may be formed in situ by a pore-former by its leaching during the operation of the system. The pore formers can be inorganic or organic and solid or liquid in nature. For example, alkaline metal salts such as sodium chloride, sodium bromide, potassium chloride, potassium sulphate, potassium phosphate etc., alkaline earth metals such as calcium chloride and calcium nitrate, carbohydrates such as sucrose, glucose, fructose, mannose, lactose, sorbitol, mannitol and, diols and polyols such as poly hyric alcohols and polyvinyl pyrrolidone can be used as pore forming agents.

\section{Coating solvent}

Solvents suitable for making polymeric solution that is used for manufacturing the wall of the osmotic device include inert inorganic and organic solvents that do not adversely harm the core, wall and other materials. The typical solvents include methylene chloride, acetone, methanol, ethanol, isopropyl alcohal, butyl alcohal, ethyl acetate, cyclohexane, carbon tetrachloride, water etc. The mixtures of solvents such as acetone-methanol (80:20), acetone-ethanol (80:20), acetone-water (90:10), methylene chloride-methanol (79:21), methylene chloride-methanol-water (75:22:3) etc. can be used (30).

\section{Plasticizers}

Different types and amount of plasticizers used in coating membrane also have a significant importance in the formulation of osmotic systems. They can change visco-elastic behavior of polymers and these changes may affect the permeability of the polymeric films (8). Some of the plasticizers used are as below:

- Polyethylene glycols

- Ethylene glycol monoacetate; and diacetate- for low permeability

- Tri ethyl citrate
- Diethyl tartarate or Diacetin- for more permeable films

\section{TYPES OF OSMOTIC PUMPS}

Based on their design and the state of active ingredient, osmotic delivery systems can be classified as follows:

\section{Osmotic delivery systems for solids}

a. Type I: Single compartment. In this design, the drug and the osmotic agent are located in the same compartment and are surrounded by the semipermeable membrane (SPM). Both the core components are dissolved by water, which enters the core via osmosis. A limitation is the dilution of drug solution with the osmotic solution, which affects the release rate of the drug from the system. Additionally, water-incompatible or water-insoluble drugs cannot be delivered effectively from a singlecompartment configuration.

b. Type II: Multiple compartments. In this design, drug is separated from the osmotic compartment by an optional flexible film, which is displaced by the increased pressure in the surrounding osmotic compartment, which, in turn, displaces the drug solution or suspension. The type II system inherently has greater utility than type I systems and can deliver drugs at a desired rate independent of their solubilities in water. One main advantage of these systems is their ability to deliver drugs that are incompatible with commonly used electrolytes or osmotic agents.

\section{Osmotic delivery systems for liquids.}

Active ingredients in liquid form are difficult to deliver from controlled release platforms because they tend to leak in their native form. Therefore, liquid active agents typically are enclosed in a soft gelatin capsule, which is surrounded by an osmotic layer that, in turn, is coated with a semipermeable membrane. When the system takes up water from its surroundings, the osmotic layer squeezes the innermost drug reservoir. The increasing internal pressure displaces the liquid from the system via a rupturing soft gelatin capsule (8). 


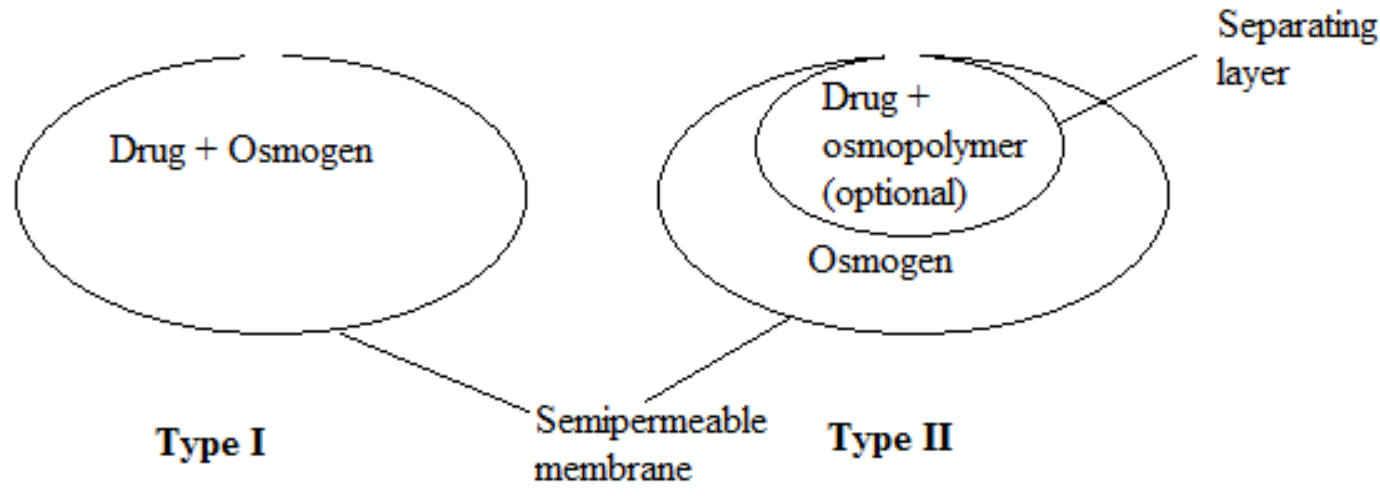

Figure 4. Classification of osmotic delivery systems: types I and II.

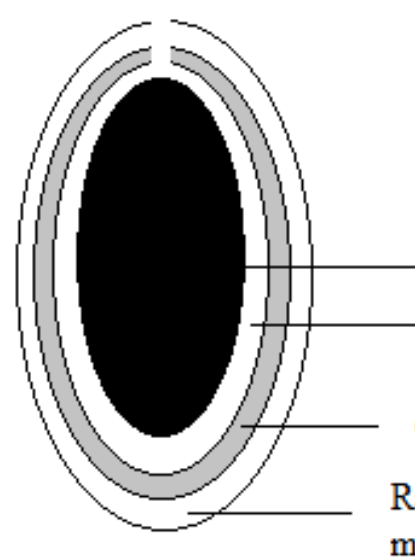

Before operation

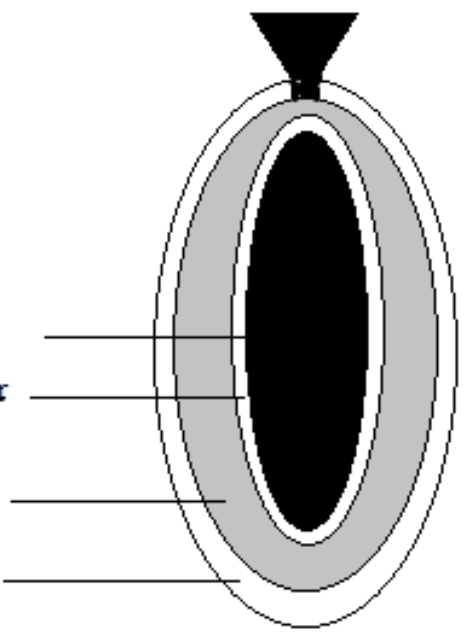

During operation

Figure 5. Osmotic delivery system for delivery of a liquid active agent.

\section{Elementary osmotic pump (EOP)}

The was introduced in 1970s to deliver drug at zero order rates for prolonged periods, and is minimally affected by environmental factors such as $\mathrm{pH}$ or motility. The tablet consists of an osmotic core containing the drug surrounded by a semipermeable membrane laser drilled with delivery orifice. Following ingestion, water in absorbed into system dissolving the drug, and the resulting drug solution is delivered at the same rate as the water entering the tablet. The disadvantages of the elementary pump are that it is only suitable for the delivery of water soluble drugs $(13,31)$.

\section{Push-Pull Osmotic Pump (PPOP)}

The two-layer push-pull osmotic tablet system appeared in 1980s. Push pull osmotic pump is a modified elementary osmotic pump through, which it is possible to deliver both poorly water-soluble and highly water soluble drugs at a constant rate. The push-pull osmotic tablet consists of two layers, one containing the drug and the other an osmotic agent and expandable agent. A semipermeable membrane that regulates water influx into both layers surrounds the system. While the push-pull osmotic tablet operates successfully in delivering water-insoluble drugs, it has a disadvantage that the complicated laser drilling technology should be employed to drill the orifice next to the drug compartment (32). 


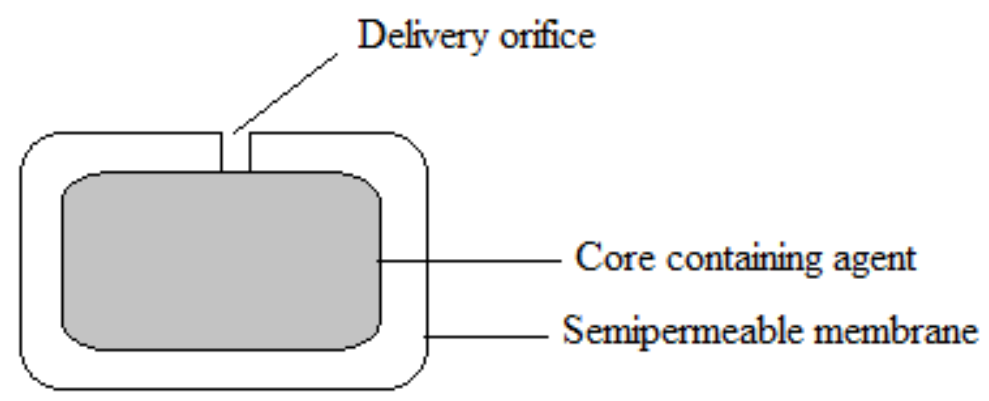

Figure 6. Elementary osmotic pump
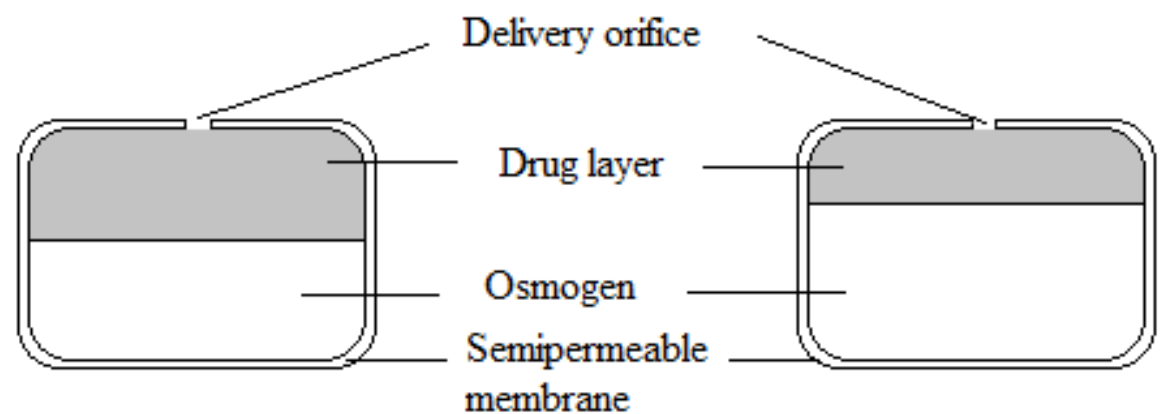

Before operation

\section{During operation}

Figure 7. Push pull osmotic pump

\section{Controlled Porosity Osmotic Pump}

A controlled porosity osmotic pump-based drug delivery system Unlike the elementary osmotic pump (EOP) which consists of an osmotic core with the drug surrounded by a semipermeable membrane drilled with a delivery orifice, controlled porosity of the membrane is accomplished by the use of different channeling agents in the coating. The CPOP contains water soluble additives in coating membrane, which after coming in contact with water; dissolve resulting in an in-situ formation of a microporous membrane. Then the resulting membrane is substantially permeable to both water and dissolved solutes and the mechanism of drug release from these system was found to be primarily osmotic, with simple diffusion playing a minor role $(33,34)$.

Drug delivery from asymmetric membrane capsule is principally controlled by the osmotic pressure of the core formation. In-situ formed delivery orifice in the asymmetric membrane in mainly responsible for the solubilization in the core for a drug with poor water solubility (35). 


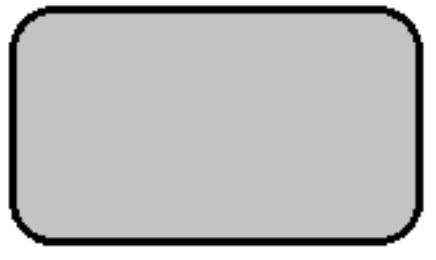

Coating containing pore forming agent
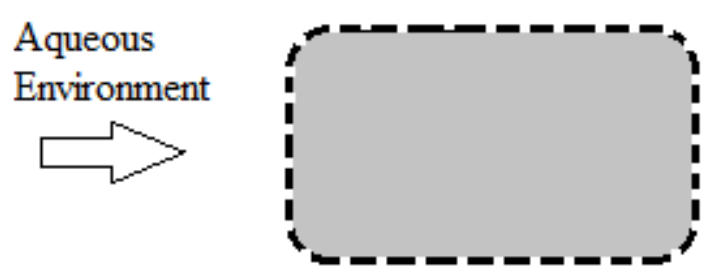

Pore formation and subsequent drug release

Figure 8. Controlled porosity osmotic pump

\section{Osmotic bursting osmotic pump}

This system is similar to an EOP expect delivery orifice is absent and size may be smaller. When it is placed in an aqueous environment, water is imbibed and hydraulic pressure is built up inside until the wall rupture and the content are released to the environment. Varying the thickness as well as the area the semipermeable membrane can control release of drug. This system is useful to provide pulsated release(16).

\section{Telescopic capsule for delayed release}

This device consists of two chambers, the first contains the drug and an exit port, and the second contains an osmotic engine. A layer of wax like material separates the two sections. To assemble the delivery device, the desired active agent is placed into one of the sections by manual or automated fill mechanism. The bilayer tablet with the osmotic engine is placed into a completed cap part of the capsule with the convex osmotic layer pointed in to the closed end of the cap and the barrier into the closed end of the cap and the barrier layer exposed towards the cap opening. The open end of the filled vessel is fitted inside the open end of the cap, and the two pieces are compressed together until the cap, osmotic bilayer tablet and vessel fit together tightly. As fluid is imbibed the housing of the dispensing device, the osmotic engine expand and exerts pressure on the slidable connected first and second wall sections. During the delay period the volume of reservoir containing the active agent is kept constant, therefore a negligible pressure gradient exists between the environment of use and interior of the reservoir. As a result, the net flow of environmental fluid driven by the pressure enter the reservoir is minimal and consequently no agent is delivered for the period $(14,36)$.

\section{OROS-CT}

OROS-CT (Alza corporation) is used as a once or twice a day formulation for targeted delivery of drugs to the colon. The OROS-CT can be a single osmotic agent or it can be comprised of as many as five to six push pull osmotic unit filled in a hard gelatin capsule.

After coming in contact with the gastric fluids, gelatin capsule dissolved and the enteric coating prevents entry of fluids from stomach to the system as the system enters into the small intestine the enteric coating dissolves and water is imbibed into the core thereby causing the push compartment to swell. At the same time flowable gel is formed in the drug compartment, which is pushed out of the orifice at a rate, which is precisely controlled, by the rate of water transport across the semi permeable membrane. Incorporation of the cyclodextrin-drug complex has also been used as an approach for delivery of poorly water soluble drugs from the osmotic systems. Ex. Sulfobutylether-Bcyclodextrin sodium salt serves as a solubilizer and osmotic agent (1). 


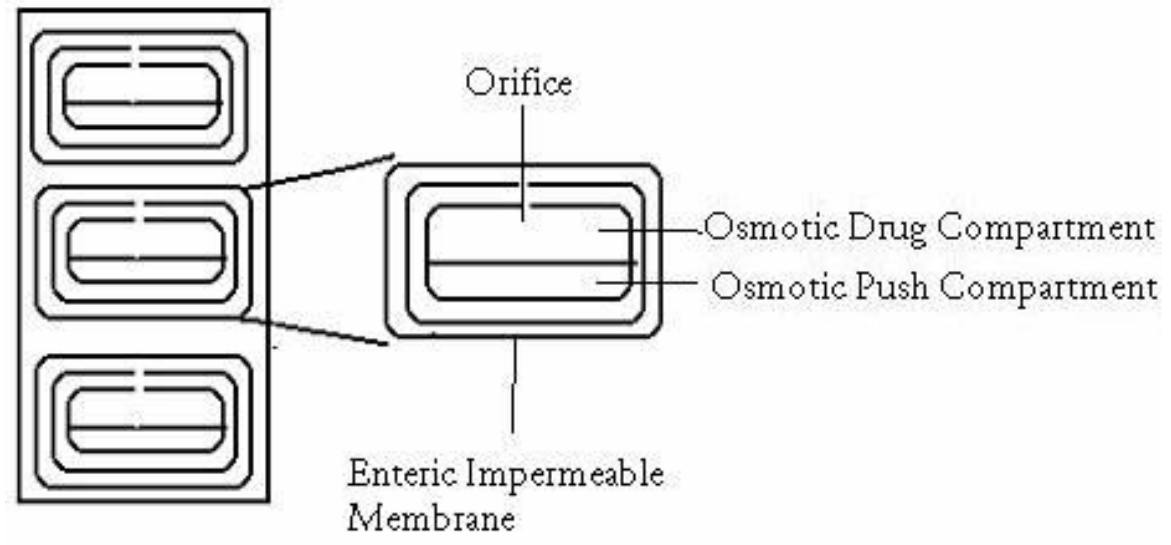

Figure 9. OROS-CT

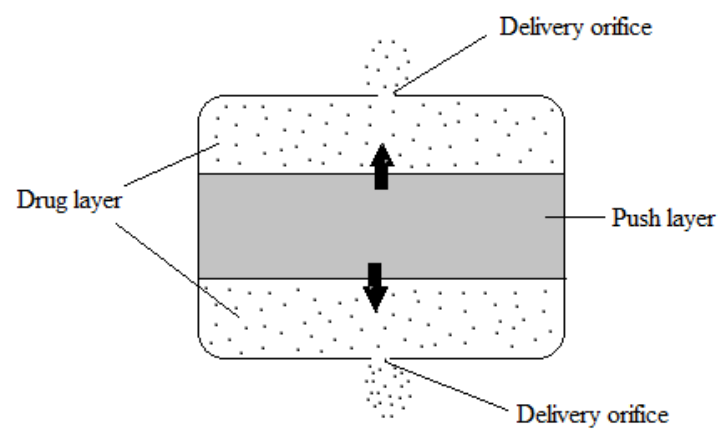

Figure 10. Sandwiched osmotic tablets

\section{Sandwiched Osmotic Tablets (SOTS)}

In this a tablet core composed of polymeric push layer sandwiched between two drug layers with two delivery orifices. When placed in the aqueous environment the middle push layer containing the swelling agent swells and the drug is released from the two orifices situated on opposite sides of the tablet and thus SOTS can be suitable for drugs prone to cause local irritation of the gastric mucosa (32).

\section{Longitudinally compressed tablet (LCT) multilayer formulation}

The LCT multilayer formulation is the advanced design. As with the push-pull system it consists of an osmotic push layer and can be configured to contain several drug layers. The opinion of multiple drug layers provides increased flexibility and control over the pattern of release of medication from the system, as opposed to the single layer used in the push-pull system, which can deliver a drug only in a zero order fashion. For example, two drug layers could be formulated with different drug concentration to provide modulation in the release rate profile. As with the push-pull formulation, water is absorbed through the exposed semipermeable tablet shell, expanding the push compartment and releasing the drug primarily through the first compartment through the laser drilled orifice at a predetermined controlled rate. After most of the drug release begins from the second compartment at a different rate. Varying the relative viscosity and hydrophilicity of the drug layer components can control the amount of mixing between the multiple drug layers. This allows even greater flexibility to achieve the target release profile. 


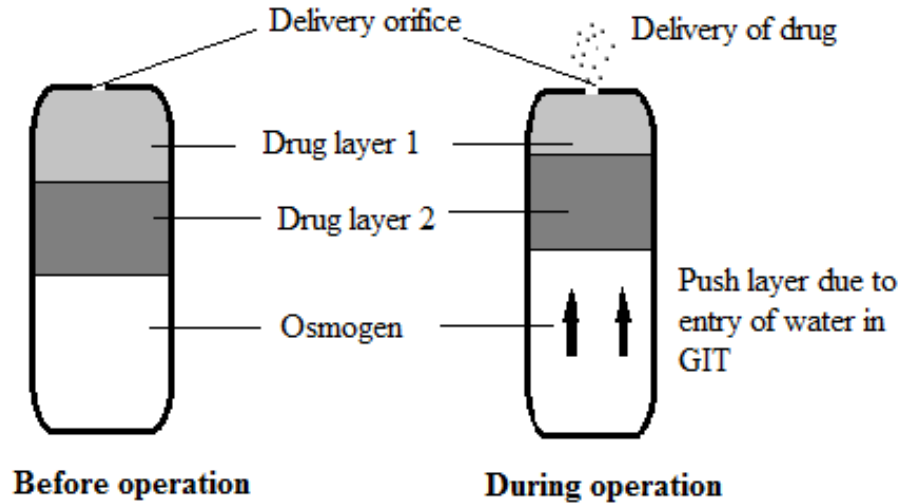

Figure 11. Multilayer osmotic pump

The LCT multilayer formulation can also be formulated with different drugs in different layers to provide combination therapy. Similar to the push-pull system, drug delivery by the LCT multilayer formulation can be unaffected by gastric $\mathrm{pH}$, gut motility and the presence of food, depending on where in the GI tract the drug is released (37).

\section{Pulsatile delivery system}

Pulsatile systems are gaining a lot of interest as they deliver the drug at the right site of action at the right time and in the right amount, thus providing spatial and temporal delivery and increasing patient compliance. These systems are designed according to the circadian rhythm of the body. The principle rationale for the use of pulsatile release is for the drugs where a constant drug release, i.e., a zeroorder release is not desired. The release of the drug as a pulse after a lag time has to be designed in such a way that a complete and rapid drug release follows the lag time. This type of tablet system consist of core coated with two layer of swelling and rupturable coatings herein they used spray dried lactose and microcrystalline cellulose in drug core and then core was coated with swelling polymer croscarmellose sodium and an outer rupturable layer of ethylcellulose.

Pulsatile systems can be classified into singleand multiple-unit systems. Single-unit systems are formulated either as capsule-based or osmosisbased systems. Single-unit systems are designed by coating the system either with eroding/soluble or rupturable coating. In multiple-unit systems, however, the pulsatile release is induced by changing membrane permeability or by coating with a rupturable membrane (38).

\section{SCIENTIFIC STUDIES}

Vincent Malaterre et.al studied on the release mechanism underlying the drug delivery from push-pull osmotic pumps (PPOP). The aim of this study was to understand which factors have an effect on the drug delivery for modelling the drug release and to develop a mathematical model predictive of the drug release kinetics. The influence of the drug property was tested on two model drugs, isradipine (ISR) and chlorpheniramine (CPA) which are respectively practically insoluble and freely soluble. Results show that, regardless of the drug properties which do not significantly affect the drug delivery, the release kinetics is mainly controlled by four factors, (i) the PEG proportion in the membrane, (ii) the tablet surface area, (iii) the osmotic agent proportion and (iv) the drug layer polymer grade (39).

Wright et.al (1992) studied an osmotic controlled release bilayer tablet for water soluble drugs. In their device, the drug compartment containing the drug and an osmopolymer, a low molecular weight CMC (as thixotropic transport means), was placed together side by side with the osmotic compartment which had a higher molecular weight $\mathrm{CMC}$ as osmotic agent preferably with another osmotically active compound. The contracting drug compartment and the pushing 
compartment were coated with semi-permeable membrane (made of cellulose ester and flux enhancer) which had an exit pore for the drug to be pushed out. Both low and high molecular weight $\mathrm{CMC}$ in the device cooperated to exhibit a high level of hydrodynamic and osmotic activity adequate for controlled delivery of the drug over the time with minimum (as little as $3.7 \%$ ) residual drug left in the device (40).

Herbig S. M. et al (1995) found a new type of asymmetric membrane tablet coatings offering significant advantages over conventional osmotic tablets. These asymmetric-membrane coatings can be used to make osmotic drug-delivery formulations with several unique characteristics. The permeability of the coating to water can be adjusted by controlling the membrane structure, thereby allowing the control of the release kinetics without altering the coating material or significantly varying its concentration. The use of asymmetric-membrane coatings on pharmaceutical tablets is described in this study; the coatings have also been applied to capsules and multi-particulate formulations (41).

Toshiaki Nagakura et al (1996) designed an osmotic pump using a semipermeable membrane that changes its volume according to the concentration of the outside solution. By a mechanochemical actuator mechanism, an insulin pump works by changing the glucose concentration. It was found that this pump may possibly be used in the treatment of diabetes mellitus patients (42).

Roger A. Rajewski et al (1999) studied the membrane controlling factors responsible for drug release from a controlled-porosity osmotic pump tablet (OPT) that utilizes sulfobutyl ether-cyclodextrin, (SBE)7m --CD, both as solubilizing agent and osmotic agent. The release rate of chlorpromazine (CLP) from OPTs containing (SBE) $7 \mathrm{~m}$--CD increased with increasing amounts of micronized lactose and decreasing amounts of triethyl citrate. The effect of lactose particle size in the membrane on drug release was studied (43).

Hai Bang Lee et al (2000) studied the sandwiched osmotic tablet system (SOTS). A sandwiched osmotic tablet core surrounded by a cellulose acetate membrane with two orifices on the surfaces of both sides was successfully prepared for the purpose of delivering nifedipine. The appropriate orifice size was observed in the range of $0.50-1.41 \mathrm{~mm}$. It was also found that the drug release rate of SOTS could be increased by incorporating hydrophilic plasticizer in the membrane, whereas it could be decreased by incorporating a hydrophobic plasticizer (44).

Sapna N et al (2003) developed a controlled porosity osmotic pump-based drug delivery system which consists of an osmotic core with the drug surrounded by a semipermeable membrane drilled with a delivery orifice, controlled porosity of the membrane is accomplished by the use of different channeling agents in the coating. The usual dose of pseudoephedrine is $60 \mathrm{mg}$ to be taken three or four times daily. It has a short plasma half life of 5-8 h. Hence, pseudoephedrine was chosen as a model drug with an aim to develop a controlled release system for a period of $12 \mathrm{~h}$. Sodium bicarbonate was used as the osmogent. The effect of different ratios of drug:osmogent on the in-vitro release was studied. Cellulose acetate (CA) was used as the semipermeable membrane. Different channeling agents tried were diethylphthalate (DEP), dibutylphthalate (DBP), dibutylsebacate (DBS) and polyethyleneglycol 400 (PEG 400). The effect of polymer loading on in-vitro drug release was studied. It was found that drug release rate increased with the amount of osmogent due to the increased water uptake, and hence increased driving force for drug release. This could be retarded by the proper choice of channeling agent in order to achieve the desired zero order release profile. Also the lag time seen with tablets coated using diethylphthalate as channeling agent was reduced by using a hydrophilic plasticizer like polyethyleneglycol 400 in combination with diethylphthalate. This system was found to deliver pseudoephedrine at a zero order rate for $12 \mathrm{~h}$. The effect of $\mathrm{pH}$ on drug release was also studied. The optimized formulations were subjected to stability studies as per ICH guidelines at different temperature and humidity conditions (7).

Roger A. Rajewski et al (2004) investigated the application of controlled-porosity osmotic pump tablet (OPT) utilizing (SBE) $7 \mathrm{~m}$--CD both as a solubilizer and an osmotic agent for drugs with varying physical properties. OPTs utilizing (SBE)7m --CD were prepared for five poorly soluble drugs such as prednisolone, estradiol, naproxen, indomethacine and chlorpromazine and for two highly water soluble drugs such as diltiazem hydrochloride and salbutamol sulfate. It was found 
that for the soluble drugs (SBE) 7m --CD acts primarily as an osmotic and an OPT control agent. Significantly, (SBE)7m --CD not only enhances the delivery of poorly soluble drugs from OPTs but acts as a controlling excipient for soluble drugs such that the release rate, corrected for tablet surface area, of both poorly soluble and soluble drugs are similar (45).

Pratim K Choudhury et al (2007) developed an asymmetric membrane capsule of cellulose acetate for osmotic delivery of flurbiprofen and influence of osmogents and solubilizing agent on in vitro drug release were evaluated. The capsule membrane was prepared by the phase inversion technique. To ensure the osmotic delivery of drug, two approaches were adopted: (i) the drug was encapsulated with osmogents like sodium chloride and mannitol to increase the osmotic pressure of the core, and (ii) the drug was encapsulated with sodium lauryl sulfate in the core of the formulation to increase the solubility and thus its osmotic pressure. Scanning electron microscopy of the membrane confirmed its porous, dense asymmetric nature. Dye test revealed in situ pore formation. The in vitro release study showed that as the proportion of osmogent and solubilizing agent was increased the release rate also increased. A good correlation was observed between the zero-order rate constant and the amount of the osmogent and solubilizing agent used (46).

Longxiao Liu et al (2008) developed the bilayer-core osmotic pump tablet (OPT) for nifedipine which does not require laser drilling to form the drug delivery orifice. The bilayer-core consisted of two layers: (a) push layer and (b) drug layer, and was made with a modified upper tablet punch, which produced an indentation at the center of the drug layer surface. The indented tablets were coated by using a conventional pan-coating process. Sodium chloride was used as osmotic agent, polyvinylpyrrolidone as suspending agent and croscarmellose sodium as expanding agent. The indented core tablet was coated by ethyl cellulose as semipermeable membrane containing polyethylene glycol 400 for controlling the membrane permeability. The in- vitro drug release profiles of various formulations were evaluated by similarity factor (f2). It was found that the optimal OPT was able to deliver nifedipine by an approximately zero- order process up to $24 \mathrm{~h}$, independent of both release media and agitation rates (47).

AK Philip et al (2008) developed an asymmetric membrane capsular system, formed in situ, for poorly water soluble drug, ketoprofen and evaluated it by both in vitro and in vivo methods for osmotic and controlled release of the drug. Membrane characterization by scanning electron microscopy showed an outer dense region with less pores and an inner porous region for the prepared asymmetric membrane (48).

Mahalaxmi.R et al (2009) developed the extended release controlled porosity osmotic pump formulations of model drug glipizide using a wicking agent and a solubilizing agent. The effect of different formulation variables like level of wicking agent, solubilizing agent, level of pore former and membrane weight gain on in vitro release were studied. Drug release was found to be affected by the level of wicking agent and solubilizing agent in the core. Glipizide release from controlled porosity osmotic pump was directly proportional to the level of pore former (sorbitol) and inversely proportional to membrane weight gain (49).

Pramod Kumar et al (2009) developed Elementary osmotic pump (EOP) of highly water soluble drug tramadol hydrochloride (TRH). Target release profile was selected and different variables were optimized to achieve the same. Formulation variables like levels of swellable polymer (10-21.87 $\%)$ and plasticizer $(0-20 \% \mathrm{w} / \mathrm{w}$ of polymer $)$, and coat thickness of semipermeable membrane (SPM) were found to affect the drug release from the developed formulations. TRH release was directly proportional to the level of plasticizer and osmotic pressure generated by osmotic agent but inversely proportional to the level of swellable polymer within the core and coat thickness of SPM. Drug release from developed formulations was independent of $\mathrm{pH}$ and agitation intensities of release media. Burst strength of the exhausted shells increased with increase in coat thickness but decreased with increase in level of plasticizer. The in-vitro results of the developed formulations were compared with performance of standard marketed formulation of TRH. The developed formulation provided more prolonged and controlled TRH release as compared to marketed formulation. The manufacturing procedure was found to be stable 
during six months of accelerated stability study (50).

Wakode Rajeshri et al (2010) developed an oral monolithic osmotic system for highly water-soluble pramipexole dihydrochloride monohydrate. Monolithic osmotic system was developed using controlled porosity membrane, this system delivers drug in controlled manner for prolonged period of time. Controlled porosity osmotic membrane consists of cellulose acetate as coating polymer and water-soluble pore formers, which forms an in-situ microporous membrane after imbibing water, hence no laser drilling is required. Pore formation was controlled by varying concentration of pore forming agents to get controlled release of pramipexole for period of $24 \mathrm{hrs}$. Scanning electron microscopy was carried out to confirm the microporous structure. An optimized system was selected to study the effect of different concentration of coating polymer, osmotic agents, $\mathrm{pH}$ of dissolution media and effect of agitation on the release of drug. From in vitro release studies it was evident that drug release was independent of $\mathrm{pH}$ and agitation but highly dependent on concentration of pore forming agents used. Increasing concentration of cellulose acetate from $2 \%-5 \% \mathrm{w} / \mathrm{v}$ drastically retarded drug release. Osmotic pressure generated was determined using 3D3 Freezing point osmometer and was found to be linear with drug release. The developed formulation gave desired once a day release of pramipexole without using laser drilling technique making it more patient compliance and cost effective (51).

Mothilal $M$ et al (2010) developed an osmotically controlled oral drug delivery system formulations of metoprolol succinate were prepared using different concentrations of mannitol, by wet granulation technique. The tablets were coated by dip coating with cellulose acetate. Stainless steel drill pins were used to make an orifice on the tablets. Tablet thickness, hardness, weight variation and drug content analysis, drug release study were performed. Orifice diameter was examined using scanning electron microscopy (SEM). With increase in osmogen content and bore size, rate of drug release were found to be increasing an optimum concentration of osmogen and bore size to give a zero order release was identified (52).

\section{MARKETED PRODUCTS}

\begin{tabular}{|c|c|c|c|c|}
\hline Trade Name & Active ingredient & Design system & Dose & Use \\
\hline Alpress LP & Prazosin & Push -Pull & $2.5-5 \mathrm{mg}$ & For the treatment of hypertension \\
\hline Acutrim & Phenylpropanolamine & Elementary pump & $75 \mathrm{mg}$ & $\begin{array}{l}\text { For the treatment the congestion } \\
\text { associated with allergies, hay fever, } \\
\text { sinus irritation, and the common cold. }\end{array}$ \\
\hline Cardura XL & Doxazosin & Push -Pull & $4,8 \mathrm{mg}$ & For the treatment of hypertension \\
\hline Covera HS & Verapamil & $\begin{array}{l}\text { Push -Pull with } \\
\text { time delay }\end{array}$ & $\begin{array}{l}180,240 \\
\mathrm{mg}\end{array}$ & $\begin{array}{l}\text { For the management of hypertension } \\
\text { and angina }\end{array}$ \\
\hline Ditropan XL & Oxybutinin chloride & Push -Pull & $5,10 \mathrm{mg}$ & $\begin{array}{l}\text { For the once daily treatment of } \\
\text { overactive bladder with symptoms of } \\
\text { urge urinary incontinence, urgency } \\
\text { and frequency }\end{array}$ \\
\hline Dynacirc CR & Isradipine & Push -Pull & $5,10 \mathrm{mg}$ & For the treatment of hypertension \\
\hline Invega & Paliperidone & Push -Pull & $3,6,9 \mathrm{mg}$ & for the treatment of schizophrenia \\
\hline Efidac 24 & $\begin{array}{l}\text { Chlorpheniramine } \\
\text { maleate }\end{array}$ & Elementary Pump & $\begin{array}{l}4 \mathrm{mg} \text { IR, } \\
12 \mathrm{mg} \mathrm{CR}\end{array}$ & $\begin{array}{l}\text { Chlorpheniramine is an antihistamine. } \\
\text { Chlorpheniramine is used to treat } \\
\text { sneezing; runny nose; itching, watery } \\
\text { eyes; hives; rashes; itching; and other } \\
\text { symptoms of allergies and the } \\
\text { common cold. }\end{array}$ \\
\hline Glucotrol XL & Glipizide & Push - Pull & $5,10 \mathrm{mg}$ & $\begin{array}{l}\text { For the control of hyperglycemia in } \\
\text { patients with non-insulin-dependent } \\
\text { diabetes }\end{array}$ \\
\hline
\end{tabular}




\begin{tabular}{|c|c|c|c|c|}
\hline Minipress XL & Prazocine & Elementary pump & $2.5,5 \mathrm{mg}$ & $\begin{array}{l}\text { Antihypertensive Agents; Alpha- } \\
\text { adrenergic Blocking Agents }\end{array}$ \\
\hline Procardia XL & Nifedipine & Push - Pull & $\begin{array}{l}30,60,90 \\
\mathrm{mg}\end{array}$ & $\begin{array}{l}\text { Calcium channel blocker. By } \\
\text { blocking calcium, nifedipine relaxes } \\
\text { and widens the blood vessels. It is } \\
\text { used to treat high blood pressure and } \\
\text { chest pain (angina). }\end{array}$ \\
\hline Sudafed 24 & Pseudoephedrine & Elementary pump & $240 \mathrm{mg}$ & $\begin{array}{l}\text { Pseudoephedrine is used for the } \\
\text { temporary relief of stuffy nose and } \\
\text { sinus pain/pressure caused by } \\
\text { infection (such as the common cold, } \\
\text { flu) or other breathing illnesses (such } \\
\text { as hay fever, allergies, bronchitis). }\end{array}$ \\
\hline Volmax & Sabutamoll & Elementary pump & $4,8 \mathrm{mg}$ & $\begin{array}{l}\text { For relief of bronchospasm in patients } \\
\text { with reversible obstructive airway } \\
\text { disease }\end{array}$ \\
\hline Tegretol XR & Carbamazepine & & $\begin{array}{l}100,200 \\
400 \mathrm{mg}\end{array}$ & For use as an anticonvulsant drug \\
\hline Viadur & Leuprolide acetate & $\begin{array}{l}\text { Implantable } \\
\text { osmotic systems }\end{array}$ & & \\
\hline Chronogesic & Sufentanil & $\begin{array}{l}\text { Implantable } \\
\text { osmotic systems }\end{array}$ & & $\begin{array}{l}\text { Anesthetics, Intravenous; Narcotics; } \\
\text { Adjuvants, Anesthesia; Analgesics, } \\
\text { Opioid; Opiate Agonists }\end{array}$ \\
\hline Concerta & Methylphenidate & $\begin{array}{l}\text { Implantable } \\
\text { osmotic systems }\end{array}$ & $\begin{array}{l}18,27,36 \\
\text { and } 54 \mathrm{mg}\end{array}$ & $\begin{array}{l}\text { A psychostimulant drug approved for } \\
\text { treatment of attention-deficit } \\
\text { hyperactivity disorder, Postural } \\
\text { Orthostatic Tachycardia Syndrome, } \\
\text { and narcolepsy. }\end{array}$ \\
\hline
\end{tabular}

\section{CONCLUSIONS}

In osmotic delivery systems, osmotic pressure provides the driving force for drug release. Increasing pressure inside the dosage form from water incursion causes the drug to release from the system. The major advantages include precise control of zero-order or other patterned release over an extended time period - consistent release rates can be achieved irrespective of the environmental factors at the delivery site. Controlled delivery via osmotic systems also may reduce the side-effect profile by moderating the blood plasma peaks typical of conventional (e.g., instant release) dosage forms. Moreover, since efficacious plasma levels are maintained longer in osmotic systems, avoidance of trough plasma levels over the dosing interval is possible. However, a complex manufacturing process and higher cost compared with conventional dosage forms limit their use. Although not all drugs available for treating different diseases require such precise release rates, once-daily formulations based on osmotic principles are playing an increasingly important role in improving patient compliance. Therefore, most of the currently marketed products are based on drugs used in long-term therapies for diabetes, hypertension, attention-deficit disorder, and other chronic disease states. Besides oral osmotic delivery systems, implants that work on osmotic principles are promising for delivery of a wide variety of molecules with a precise rate over a long period of time. Further, with the discovery of newer and potent drugs by the biotechnology industry, the need to deliver such compounds at a precise rate certainly will pave the way for osmotic delivery systems to play an increasingly important role in drug delivery. 


\section{REFERENCES}

1. Madhavi BB, Nath AR, Banji D, Ramalingam R, Madhu MN, Kumar DS. Osmotic drug delivery system: a review. Pharmakine, dec 2009;2:5-14.

2. Prescott, L.F, The need for improved drug delivery in clinical practice, in: Prescott LF, Nimmo WS (eds), Novel Drug Delivery and Its Therapeutic Application, John Wiley, UK, pp 1-11, 1989.

3. Sastry SV, DeGennaro MD, Reddy IK, Khan MA. Atenolol gastrointestinal therapeutic system Part 1: Screening of formulation variables. Drug Dev Ind Pharm 1997; 23: 2:157-165.

4. Mishra B,Makesh BK, Sankar C. Oral push-pull osmotic pumps of pentazocine hydrochloride: development and evaluation. Ind J Pharm Sci, 2006; 68:1:85-87.

5. Verma RK, Krishna DM, Garg S. Formulation aspects in the development of osmotically controlled oral drug delivery systems. J Control Release, 2002; 79:7-27

6. YANG Xing-Gang, ZHANG Guo-Hua, LI Wei, PENG Bo, LIU Zhi-Dong, PAN Wei-San. Design and Evaluation of Jingzhiguanxin Monolithic Osmotic Pump Tablet. Chem Pharm Bull, 2006; 54: 4:465-469.

7. Makhija Sapna N, Vavia Pradeep R. Controlled porosity osmotic pump-based controlled release systems of pseudoephedrine I: Cellulose acetate as a semipermeable membrane. J Control Release, 2003; 89:5-18

8. Srikonda Sastry, Kotamraj Phanidhar, Barclay Brian, Osmotic controlled drug delivery system, in Li Xiaoling, Jasti Bhaskara R (eds), Design of Controlled Release Drug Delivery Systems, McGraw-Hill Companies, INC, New York, pp 203229,2006

9. McClelland GA, Sulton SC, Engle K, Zentner GM. The solubility-modulated osmotic pump: invitro / invivo release of diltiazem hydrochloride. Pharma Res 1991; 8:88-92.

10. Rose S, Nelson JF. A continuous long-term injector. Aust J Exp Biol, 1955; 33:415

11. Higuchi T, Leeper HM. Improved osmotic dispenser employing magnesium sulfate and magnesium chloride. US Patent 3760804, 1973.

12. Higuchi T, Leeper HM. Osmotic dispenser with means for dispensing active agent responsive to osmotic gradient. US Patent 3995631, 1976.

13. Theeuwes, F. Elementary Osmotic Pump. J Pharm Sci, 1975; 64:1987-1991.

14. Kaushal AM, Garg S. An update on osmotic drug delivery patents. Pharm Tech, Aug 2003; 27:38-44.
15. Bhatt PP. Osmotic drug delivery systems for poorly soluble drugs. The drug delivery companies report autumn/winter 2004.

16. Parmar NS, Vyas SK, jain NK. Advances in controlled and novel drug delivery. CBS publisher \& distributors, New Delhi, pp 18-39, 2001.

17. Eckenhoff, Yum SI. The osmotic pump: novel research tool for optimizing drug regimen. Biomaterials, 1981; 2:89-97

18. Good WR, Lee PI. Membrane-controlled reservoir drug delivery systems, in Langer RS, Wise DL (eds), Medical Applications of Controlled Release, I Vol., Boca Raton, CRC Press, pp 1-39, 1984.

19. Theeuwes F, Higuchi T. Osmotic dispensing device with maximum and minimum sizes for the passageway. US Patent 3916899, 1975.

20. Gaebler, F. Laser drilling enables advanced drug delivery systems. Coherent article for Pharm Manufacturing, Jan 2007;1-7.

21. Theeuwes F, Saunders RJ, Mefford WS. Process for forming outlet passageways in pills using a laser. US Patent 4088864; 1978.

22. Liu L, Wang X. Solubility modulated monolithic osmotic pump tablet for atenolol delivery. Eur J Pharm Biopharm 2008; 68: 2:298-302.

23. Khanna, SC. Therapeutic system for sparingly soluble active ingredients. Ciba-Geigy Corporation, Ardsley, NY, US Patent 4992278, 1997.

24. Zentner GM, McClelland GA, Sutton SC. Controlled porosity solubility- and resin-modulated osmotic drug delivery systems for release of diltiazem hydrochloride. J Control Release, 1991; 16:1-2:237-243.

25. Okimoto K, Ohike A, Ibuki R, et al. Design and evaluation of an osmotic pump tablet (OPT) for prednisolone: a poorly water soluble drug using (SBE)7m-beta-CD. Pharm Res, 1998; 15: 10:15621568.

26. Theeuwes F, Swanson DR, Guittard G, et al. Osmotic delivery systems for the beta-adrenoceptor antagonists metoprolol and oxprenolol: Design and evaluation of systems for once-daily administration. Br J Clin Pharmacol, 1985;19: 2:69S-76S.

27. Santus G, Baker RW. Osmotic drug delivery: A review of the patent literature. J Control Release, 1995;35: 1:1-21.

28. Eckenhoff B, Theeuwes F, Urquhart J. Osmotically actuated dosage forms for rate-controlled drug delivery. Pharm Technol 1987; 11:96-105.

29. Jensen JL, Appel LE, Clair JH, Zentner GM. Variables that affect the mechanism of drug release from osmotic pumps coated with 
acrylate/methacrylate copolymer latexes. J Pharm Sci, 1995; 84: 5:530-533.

30. Vyas, S.P.; Khar, R.K., Controlled drug delivery: concept and advances. Vallabh prakashan, New Delhi, pp 477-501, 2001.

31. Theeuwes F, Swanson D, Wong P, Bonsen P, Place V, Heimlich K, Kwan KC. elementary osmotic pump for indometacin. J pharm Sci 1983; 72:253258.

32. Liu L, Ku J, Khang G, Lee B, Rhee JM, Lee HB. Nifedipine controlled delivery by sandwiched osmotic tablet system. J Control Release, 2000; 68:145-156.

33. Haslem J, Rork GS. Controlled porosity osmotic pump. US Patent 488063, 1989.

34. Thombrea AG, Cardinall JR, DeNoto AR, Herbig SM, Smith KL. Asymmetric membrane capsules for osmotic drug delivery: Development of a manufacturing process. J Control Release, 1999; 57:55-64.

35. Zentner GM, Rork GS, Himmelsteine KJ. osmotic flow through controlled porosity films: an approach to deliver water soluble compounds. J Control Release, 1985; 2:217-229.

36. Theuwes, F.; Wong, P.S.L.; Burkoth, T.L.; Fox, D.A.; Bicek, P.R., Colonic drug absorption and metabolism. Marcel Decker, New York, pp 137-158, 1993.

37. Conley R, Gupta SK, Satyan G. Clinical spectrum of the osmotic controlled release oral delivery system (OROS): an advanced oral delivery form. Current medical research and opinion, 2006; 22:1879-1892.

38. Arora S, Ali J, Ahuja A, Baboota S, Qureshi J. Pulsatile drug delivery systems: An approach for controlled drug delivery. Ind J Pharm Sci, 2006; 68: 3:295-300.

39. Malaterre V, Metz H, Ogorka J, Mader K, Gurny R, Loggia N. Influence of the hydration kinetics and the viscosity balance on the drug release performance of push-pull osmotic systems. Novartis Pharma AG, Technical R\&D, Fabrikstrasse 2, CH4056 Basel, Switzerland, 1-2.

40. Wright JD,Barelay BL, Swanson DR. International Patent, WO 92/18102

41. Herbig SM, Cardinal JR, Korsmeyer KL, Smith KL. Asymmetric-membrane tablet coatings for osmotic drug delivery. J Control Release, 1995; 35:127-136.
42. Nagakura T, Ishihara K, Furukawa T, Masuda K, Tsuda T. Auto-regulated Osmotic pump for insulin therapy by sensing glucose concentration without energy supply. Sensors and Actuators B, 1996; 34: 229-233.

43. Roger RA, et al. Factors affecting membrane controlled drug release for an osmotic pump tablet utilizing (SBE)7m --CD as both a solubilizer and osmotic agent. J Control Release, 1999; 60:311-319.

44. Lee HB, Liu L, Ku J, Khang G, Lee B, Rhee JM. Nifedipine controlled delivery sandwiched osmotic tablet system. J Control Release, 2000; 68:145-156.

45. Roger RA, et al. Applicability of (SBE)7m --CD in controlled-porosity osmotic pump tablets (OPTs). Int J Pharm, 2004; 286:81-88.

46. Choudhury PK, Ranawat MS, Pillai MK, Chauhan CS. Asymmetric membrane capsule for osmotic delivery of flurbiprofen. Acta Pharm, 2007; 57:343350.

47. Liu L, Xu X. Preparation of bilayer-core osmotic pump tablet by coating the indented core tablet. Int J Pham, 2008; 352: 1-2:225-230.

48. Philip AK, Pathak K. In situ formed phase transited drug delivery system of ketoprofen for achieving osmotic controlled and level a in vitro in vivo correlation. Ind J pharm Sci, 2008; 70: 6:745-753.

49. Mahalaxmi R, Sastri P, kumar R, Kalra A, Kanagale $P$, Narkhede. Enhancement of Dissolution of Glipizide from Controlled Porosity Osmotic Pump Using a Wicking Agent and a Solubilizing Agent. Int J PharmTech Res, 2009; 1: 3:705-711.

50. Kumar Pramod, Singh Sanjay, Mishra Brahmeshwar. Development and Evaluation of Elementary Osmotic Pump of Highly Water Soluble Drug: Tramadol Hydrochloride. Current Drug Delivery, 2009; 6:130-139.

51. Rajeshri Wakode, Varma MM. Once a day osmotic drug delivery system for highly water soluble Pramipexole. J Chem Pharm Res, 2010; 2: 2:136146.

52. Mothilal M, Damodharan N, Lakshmi KS, Sharanya VB, Srikrishna T. Formulation and invitro evaluation of osmotic drug delivery system of metoprolol succinate. Int J Pharm Pharm Sci, 2010; 2: 2:64-68. 